O CONFLITO ENTRE OS “FANÁTICOS” E A "POLÍCIA HEROICA": MEMÓRIAS DE CANUDOS NOS JORNAIS E EM VERSOS DE CORDEL NO PARÁ (1897-1940)

Patrícia dos Santos Lieuthier Freitas \& Geraldo Magella de Menezes Neto

\title{
O CONFLITO ENTRE OS "FANÁTICOS" E A "POLÍCIA HEROICA": MEMÓRIAS DE CANUDOS NOS JORNAIS E EM VERSOS DE CORDEL NO PARÁ (1897-1940)
}

\section{THE CONFLICT BETWEEN THE "FANATICS" AND THE "HEROIC POLICE": MEMORIES OF CANUDOS IN THE NEWSPAPERS AND IN CORDEL VERSES IN PARÁ STATE, BRAZIL (1897-1940)}

\author{
Patrícia dos Santos Lieuthier Freitas ${ }^{1}$ \\ Geraldo Magella de Menezes Neto ${ }^{2}$
}

\begin{abstract}
RESUMO: Este trabalho propõe uma análise das memórias da Guerra de Canudos veiculadas nos jornais paraenses A Província do Pará e Folha do Norte no ano de 1897, e o folheto de cordel História de Antônio Conselheiro (Campanha de Canudos, narração completa) de Arinos de Belém. Analisa-se o discurso dos periódicos e do cordel a respeito de Antônio Conselheiro e seus seguidores e sobre a participação da Polícia Militar do Pará no conflito, observando as permanências e mudanças em relação à imagem construída sobre esses sujeitos. Percebe-se por meio da pesquisa que esses veículos de mídia reproduziam uma visão pejorativa do beato e dos canudenses e retratavam as tropas como heroicas, sustentando o mesmo discurso de que era necessário combater Canudos.
\end{abstract}

PALAVRAS-CHAVE: Canudos; Imprensa. Literatura de cordel

ABSTRACT: This article proposes an analysis from the memories of the Canudos War conveyed in the Pará state's periodicals A Província do Pará and Folha do Norte in the year of 1897, and cordel booklets História de Antônio Conselheiro (Campanha de Canudos, narração completa) by Arinos de Belém. The periodical discourse and the cordel about Antonio Conselheiro and his followers and about the participation of the Military Police of Pará was analyzed, observing the permanences and changes in relation to the image constructed on these individuals. It can be seen from the research that these media vehicles reproduced a pejorative vision of the blessed and the Canudenses and portrayed the troops as heroic, sustaining the same discourse that it was necessary to defeat Canudos.

KEYWORDS: Canudos War, Cordel Literature; Press.

\footnotetext{
${ }^{1}$ Graduada em História pela Universidade Federal do Pará (UFPA). Especialista em Amazônia: História, Espaço e Cultura pela Faculdade Integrada Brasil Amazônia (FIBRA). E-mail: patriciaslfreitas@yahoo.com.br

${ }^{2}$ Professor da graduação e da pós-graduação em História da Faculdade Integrada Brasil Amazônia (FIBRA), e do ensino fundamental da Secretaria Municipal de Educação de Belém (SEMEC). Doutorando em História Social da Amazônia pela Universidade Federal do Pará (UFPA). E-mail: geraldoneto53@hotmail.com
} 


\section{HISTÓRIA \\ O CONFLITO ENTRE OS "FANÁTICOS” E A "POLÍCIA HEROICA": MEMÓRIAS DE CANUDOS NOS JORNAIS E EM VERSOS DE CORDEL NO PARÁ (1897-1940) \\ Patrícia dos Santos Lieuthier Freitas \& Geraldo Magella de Menezes Neto}

Introdução

Nos primeiros anos do regime republicano o Brasil passa por crises e instabilidade política. Nesse momento surgem várias revoltas sociais, como o movimento de Canudos que teve significativa notoriedade na imprensa e gerou grande mobilização por parte dos governantes para sua repressão, episódio que ficou conhecido como Guerra de Canudos (Bahia, 1896-1897). Segundo Lidiane Pinheiro este fato pode ser considerado "um dos maiores eventos da imprensa brasileira". (PINHEIRO, 2012, 17).

Este acontecimento foi bastante divulgado no estado do Pará, em veículos da mídia como nos jornais A Província do Pará e Folha do Norte, no ano de 1897; e foi tema de vários folhetos de cordel, inspirando, por exemplo, o poeta Arinos de Belém a escrever o folheto História de Antonio Conselheiro (Campanha de Canudos, narração completa), publicado em 1940 pela editora Guajarina de Belém do Pará. (BELÉM, 1940).

Neste trabalho pretendemos fazer uma discussão acerca da memória de Canudos, a partir da análise comparativa das notícias sobre este fato publicadas nos jornais e no cordel escrito por Arinos de Belém, com o objetivo de perceber as permanências e mudanças a respeito da imagem de Antonio Conselheiro e seus seguidores e da atuação da Polícia Militar do Pará na guerra.

Alguns trabalhos debatem as repercussões de Canudos na imprensa paraense, a exemplo de Jacob Lima em sua monografia Expedição paraense em Canudos e o republicanismo de 1897, onde o autor analisa reportagens sobre a participação do regimento e obras literárias a respeito da República para discutir o republicanismo paraense. (LIMA, 2006).

Também foram importantes para a pesquisa os trabalhos a respeito da participação da polícia paraense na campanha, os significados e os debates políticos e na imprensa em torno disso: A brigada militar do Pará na Guerra de Canudos de William Gaia Farias e Em defesa da República: Os soldados paraenses na Guerra de Canudos de Welton Monteiro.

Da mesma forma, a relação entre imprensa e literatura de cordel já foi abordada nos artigos Imprensa e poesia de cordel nas primeiras décadas do século $X X$ no Pará de Franciane Gama Lacerda e A notícia em versos: relações entre jornais e folhetos de cordel no Pará na primeira metade do século XX de Geraldo Magella de Menezes Neto. Lacerda aponta nesse trabalho a possibilidade de se estudar história da Amazônia a partir de folhetos de cordel e suas ligações com órgãos jornalísticos. (LACERDA, 2008, 11). Menezes Neto estuda essa conexão a partir da comparação entre reportagens sobre o "crime da Praça da República" e dois folhetos escritos por Arinos de Belém sobre o caso, com o objetivo de 


\title{
HISTORIA \\ O CONFLITO ENTRE OS "FANÁTICOS" E A "POLÍCIA HEROICA": MEMÓRIAS DE CANUDOS NOS JORNAIS E EM VERSOS DE CORDEL NO PARÁ (1897-1940) \\ Patrícia dos Santos Lieuthier Freitas \& Geraldo Magella de Menezes Neto
}

entender como ocorrem as transformações das notícias em versos de cordel. (MENEZES NETO, 2011, 53).

Ao trabalharmos com a ideia de memória para analisarmos as imagens sobre Canudos nos jornais e na literatura de cordel, consideramos importante o que nos diz Pierre Nora, que considera que:

A memória é a vida, sempre carregada por grupos vivos e, nesse sentido, ela está em permanente evolução, aberta à dialética da lembrança e do esquecimento, inconsciente de suas deformações sucessivas, vulnerável a todos os usos e manipulações, suscetível de longas latências e repentinas modificações. (NORA, 1993, 9).

Michael Pollak relaciona a memória com o reforço da coesão e identidade de grupos, como o de um Estado nacional, por exemplo. Nessa construção de uma memória comum, há também a delimitação de fronteiras, que excluem grupos e ideias consideradas como uma ameaça à identidade comum:

\begin{abstract}
A memória, essa operação coletiva dos acontecimentos e das interpretações do passado que se quer salvaguardar, se integra, como vimos, em tentativas mais ou menos conscientes de definir e de reforçar sentimentos de pertencimento e fronteiras sociais entre coletividades de tamanhos diferentes: partidos, sindicatos, igrejas, aldeias, regiões, clãs, famílias, nações etc. A referência ao passado serve para manter a coesão dos grupos e das instituições que compõem uma sociedade, para definir seu lugar respectivo, sua complementariedade, mas também as oposições irredutíveis. (POLLAK, 1989, 10)
\end{abstract}

Assim como qualquer outro evento considerado por uma sociedade como significativo, Canudos foi objeto de lembrança em outras épocas, tendo a sua memória reelaborada diversas vezes. Dessa forma, os jornais e a literatura de cordel são fontes relevantes para entendemos essas construções e reconstruções do imaginário sobre Canudos até mesmo em locais distantes em que não se desenrolaram os acontecimentos, como no Pará.

Iniciaremos o artigo com uma breve biografia de Antônio Conselheiro e a contextualização histórica da Guerra de Canudos. Na segunda parte, analisamos como a Folha do Norte e a Província do Pará noticiaram este acontecimento na época do conflito. Por fim, analisamos como a memória do evento é retomada na década de 1940 pelo poeta Arinos de Belém.

\section{A Guerra de Canudos}




\section{HISTÓRIA \\ O CONFLITO ENTRE OS “FANÁTICOS” E A "POLÍCIA HEROICA": MEMÓRIAS DE CANUDOS NOS JORNAIS E EM VERSOS DE CORDEL NO PARÁ (1897-1940) \\ Patrícia dos Santos Lieuthier Freitas \& Geraldo Magella de Menezes Neto}

Antonio Vicente Mendes Maciel nasceu por volta do ano de 1830 em Quixeramobim no Ceará; filho de Maria Joaquina de Jesus e Vicente Mendes Maciel, que era dono de um estabelecimento comercial. Ele fazia parte "de uma família tradicionalmente católica e recebia influências do catolicismo popular" (MONTENEGRO apud ANDRADE, 2006, 20).

Após a morte do pai assume o estabelecimento, que vai à falência alguns anos depois. Posteriormente Antônio resolve ir embora da cidade com a primeira esposa, Brasilina, mudando-se várias vezes e exercendo trabalhos como caixeiro, escrivão, solicitador. Continua a mudar de residência após ela o abandonar. Passado algum tempo inicia uma relação com Joana Imaginária, mulher que esculpia imagens de santos, com quem se dedica a estudar Sagradas Escrituras e começa a pregar e dar conselhos aos necessitados.

Quando a relação termina, inicia sua peregrinação por cidades nordestinas, por volta da década de 1870. Nesse momento começa a atrair seguidores que o acompanham ao longo de suas pregações e realizam obras como construção e reparo de igrejas, cemitérios e açudes.

Após enfrentarem conflitos com autoridades em alguns dos lugares que passaram ao longo de duas décadas de peregrinação, em 1893 estabelecem-se nas terras de uma fazenda abandonada à margem do rio Vaza-barris ${ }^{3}$. O arraial seria "batizado" de Belo Monte, mas ficaria conhecido por Canudos. A cidadela atraiu muitos sertanejos e causou preocupação na Igreja e nos proprietários de terra. A Igreja temia a perda de fieis e os latifundiários a perda da mão de obra, uma vez que ocorria um êxodo dos trabalhadores rurais que iam para Canudos. Os que lá foram morar trabalhavam com a agricultura e mantinham relações comerciais com cidades vizinhas

O conflito se inicia em novembro de 1896, quando um comerciante da cidade de Juazeiro não entrega a madeira encomendada por eles para a construção da Igreja Nova, os compradores dizem que vão busca-la pessoalmente, o que serve de pretexto para o envio de tropas policiais, comandadas pelo tenente Pires Ferreira, com a justificativa de proteger a cidade, que segundo as autoridades locais estaria ameaçada. Essa seria considerada como a primeira expedição. As tropas partiram de Juazeiro e de lá seguiram para Uauá onde entraram em confronto com os canudenses. O combate durou cinco horas e após notarem que não resistiriam mais, as forças policiais se retiram, voltando a Juazeiro.

Ainda são enviadas mais três expedições para combater Canudos. A Polícia Militar do Pará fez parte da $4^{\mathrm{a}}$ e última expedição, comandada pelo general Arthur Oscar, com o efetivo

\footnotetext{
${ }^{3}$ Rio que banha os estados de Sergipe e Bahia 


\section{HISTÓRIA \\ O CONFLITO ENTRE OS “FANÁTICOS” E A "POLÍCIA HEROICA": MEMÓRIAS DE CANUDOS NOS JORNAIS E EM VERSOS DE CORDEL NO PARÁ (1897-1940) \\ Patrícia dos Santos Lieuthier Freitas \& Geraldo Magella de Menezes Neto}

calculado entre 10 mil e 12 mil combatentes, composta ainda por tropas do exército e pelos batalhões de polícia de São Paulo, Bahia e Amazonas.

O regimento paraense parte para a Bahia no dia 5 de agosto de 1897, sob o comando do coronel José Sotero de Menezes, composto por um efetivo de 547 homens, entre combatentes, oficiais e médicos. Chegam a Canudos no dia 16 de Setembro de 1897 e entram em combate no dia 25 de setembro ${ }^{4}$, junto com as tropas da Polícia do Amazonas e do exército e nesse momento conseguem entrar em Canudos e tomar parte do arraial. Nesta batalha o tenente-coronel Sotero de Menezes acaba sendo ferido, sendo substituído no comando de sua tropa pelo tenente-coronel Antônio Sérgio Dias Vieira de Fontoura, que posteriormente seria considerado como patrono da Polícia Militar do Pará.

A tomada do arraial pelas forças federais ocorre no dia 5 de outubro de 1897 , sendo a cidadela incendiada. Muitos dos canudenses foram feitos prisioneiros, vários deles degolados. Antonio Conselheiro morreu um pouco antes da tomada de Canudos, em 22 de setembro de 1897.

As tropas paraenses se retiram de Canudos no dia 8 de outubro, seguindo para Salvador, aonde chegam no dia 16 do mesmo mês. Partem desta cidade para a capital paraense no dia 23 de outubro, chegando a Belém na manhã de 4 de novembro de 1897, sendo recebidos com grande celebração e recebendo promoções do Governo do estado.

A vitória das tropas legalistas sobre Canudos em um primeiro momento, em discurso, significou a fidelidade do governo federal aos ideais republicanos, eliminando um suposto antro monarquista e politicamente culminou em um fortalecimento dos grupos republicanos ligados ao presidente Prudente de Moraes. Em um segundo momento, ao se perceber que os moradores do arraial não tinham ligação com grupos monarquistas e ao se tomar conhecimento dos métodos adotados pelas mesmas para combater os sertanejos, muda-se o discurso, surgindo manifestações de mea culpa. Além disso, o exército que antes era considerado como o defensor da pátria e da República, mesmo sendo realizadas festas e comemorações em virtude de sua atuação, sairia da campanha coberto de opróbrio. ${ }^{5}$

O conflito de Canudos não terminou com a morte de Antônio Conselheiro. As memórias do evento foram continuamente reforçadas e reelaboradas décadas após o fim do

\footnotetext{
${ }^{4}$ William Gaia Farias conta que a atuação da Polícia Militar do Pará nesta batalha ainda é lembrada no hino da instituição, mantido até a atualidade, e deu nome à Avenida 25 de setembro (atual Rômulo Maiorana), no bairro do Marco. (FARIAS, 2010, 70).

${ }^{5}$ Esta breve descrição dos eventos de Canudos foi feita baseada em HERMANN, 1996; GALVÃO, 2001; MONIZ, 2001; FARIAS, 2010; MONTEIRO, 2011.
} 


\section{HISTÓRIA \\ O CONFLITO ENTRE OS "FANÁTICOS” E A "POLÍCIA HEROICA": MEMÓRIAS DE CANUDOS NOS JORNAIS E EM VERSOS DE CORDEL NO PARÁ (1897-1940) \\ Patrícia dos Santos Lieuthier Freitas \& Geraldo Magella de Menezes Neto}

arraial de Canudos. Grande papel teve Euclides da Cunha, com a obra Os Sertões, de 1902, e também a imprensa, a literatura de cordel, o cinema, enfim, vários meios pelos quais circularam as histórias da guerra. Nesse sentido, como enfatiza Pollak:

Mas nenhum grupo social, nenhuma instituição, por mais estáveis e sólidos que possam parecer, têm sua perenidade assegurada. Sua memória, contudo, pode sobreviver a seu desaparecimento, assumindo em geral a forma de um mito que, por não poder se ancorar na realidade política do momento, alimenta-se de referências culturais, literárias ou religiosas. 0 passado longínquo pode então se tornar promessa de futuro e, às vezes, desafio lançado à ordem estabelecida. (POLLAK, 1989, 12-13).

Canudos sobreviveu como memória em variadas fontes que estão disponíveis hoje, legando ao presente múltiplas visões sobre o evento, ora favoráveis as tropas governistas, ora favoráveis ao movimento liderado por Conselheiro. Há assim, múltiplas memórias, porque "há tantas memórias quantos grupos existem; que ela é, por natureza, múltipla e desacelerada, coletiva, plural e individualizada." (NORA, 1993, p. 9). Nosso objetivo é investigar as construções dessas variadas memórias a partir de fontes diversas como a imprensa e a literatura de cordel.

O discurso dos jornais paraenses sobre Canudos: Folha do norte e A Província do Pará.

A imprensa paraense atuou fortemente na cobertura dos desdobramentos da Campanha contra Canudos, defendo as expedições e contribuindo para a construção da imagem dos sertanejos como "inimigos da República". Dentre os principais jornais que circulavam na cidade de Belém nessa época e que noticiaram a contenda estavam $A$ Província do Pará e Folha do Norte ${ }^{6}$.

A Província do Pará foi um jornal de circulação diária, fundado no ano de 1876 por Joaquim José de Assis, que exercia o cargo de redator político; Francisco de Souza Cerqueira, tipógrafo e Antônio José de Lemos$^{7}$, redator gerente. Originou-se do jornal maçônico O Pelicano, que foi vendido para Francisco Souza Cerqueira e depois para Joaquim José de Assis. Durante a monarquia foi órgão do Partido Liberal, depois se tornando uma

\footnotetext{
${ }^{6}$ Esses jornais podem ser encontrados na seção de microfilmes da Biblioteca Pública Arthur Vianna da Fundação Cultural do Pará (CENTUR).

${ }^{7}$ Político paraense. Foi intendente da cidade de Belém no final do século XIX e início do século XX que empreendeu projeto político pautado na questão da modernização e embelezamento da cidade (SARGES, 2010).
} 


\section{HISTÓRIA \\ O CONFLITO ENTRE OS "FANÁTICOS" E A "POLÍCIA HEROICA": MEMÓRIAS DE CANUDOS NOS JORNAIS E EM VERSOS DE CORDEL NO PARÁ (1897-1940) \\ Patrícia dos Santos Lieuthier Freitas \& Geraldo Magella de Menezes Neto}

empresa comercial. Teve seu primeiro número publicado no dia 25 de março de 1876. (BIBLIOTECA PÚBLICA DO PARÁ, 1985, 72; FARIAS, 2005, 38).

Já a Folha do Norte é fundada no ano de 1896 por Enéas Martins, Cipriano Santos e outros. Também circulava diariamente e tinha como objetivo "lutar pelo desenvolvimento político e social da região, combatendo a política de Antônio Lemos" (BIBLIOTECA PÚBLICA DO PARÁ, 1985, 154), que na época era proprietário de A Província do Pará. Seu primeiro número foi publicado no dia $1^{\circ}$ de janeiro de 1896. Segundo Marilene Neves, a Folha do Norte vai ser caracterizada em toda a sua existência por fazer oposição ao governo, sendo também o único jornal a fazê-la, centrado na pessoa de Paulo Maranhão, que passa a fazer parte do diário no ano de 1897. (NEVES, 1993, 7)

Inicialmente esses jornais dão visibilidade à guerra através de telegramas enviados por correspondentes ${ }^{8}$ em estados como Rio de Janeiro, Bahia e São Paulo. Relatam a organização das expedições, o investimento em material bélico e as batalhas ${ }^{9}$.

A Província do Pará publica o primeiro telegrama sobre Canudos na edição de 12 de janeiro de 1897 informando que tropas sob o comando do major Febrônio de Brito estavam sendo organizadas "para combater o audaz caudilho Antonio Conselheiro" (A PROVÍNCIA DO PARÁ, 12 jan. 1897, 2), que seria a segunda expedição contra o arraial. A publicação ressaltava que "as forças d'este bandido acham-se em Canudos" (A PROVÍNCIA DO PARÁ, 12 jan. 1897, 2). No dia 29 de janeiro de 1897 outro telegrama traz novas informações sobre as operações dessa expedição e especula sobre a quantidade de moradores de Canudos, segundo o correspondente "o numero d'esses bandidos atinge 2.000, todos bem armados e municiados” (A PROVÍNCIA DO PARÁ, 29 jan. 1897, 2).

No dia 31 de janeiro de 1897 é veiculado um telegrama onde o correspondente pretende relatar "importantes e assustadores pormenores do theatro da lucta entre as forças legaes e as hostes de Antonio conselheiro" (A PROVÍNCIA DO PARÁ, 31 jan. 1897, 2). Segundo o correspondente, notícias oficiais informavam que Conselheiro dispunha de "cinco mil combatentes, tendo em sua companhia egual número formado por homens inválidos, mulheres e creanças"e que recebia armas e munições "do alto sertão do paiz". Afirma que "o desalmado já saqueou 60 fazendas" e que prometia "o sicário arrazar tudo, para dividir as propriedades com os sequazes”. (A PROVÍNCIA DO PARÁ, 31 jan. 1897, 2).

\footnotetext{
${ }^{8}$ Não encontramos referências nas fontes sobre a identidade dos jornalistas.

${ }^{9}$ Manteremos a grafia original das fontes. 
O CONFLITO ENTRE OS "FANÁTICOS" E A "POLÍCIA HEROICA": MEMÓRIAS DE CANUDOS NOS JORNAIS E EM VERSOS DE CORDEL NO PARÁ (1897-1940)

Patrícia dos Santos Lieuthier Freitas \& Geraldo Magella de Menezes Neto

Logo nas primeiras notas divulgadas pelo noticiário, percebe-se que o mesmo incorpora e reproduz o discurso sustentado pela imprensa nacional de que Canudos representava perigo como no trecho no qual o autor afirma que Conselheiro havia saqueado fazendas e que prometia "arrasar tudo". Nos telegramas vemos serem atribuídos adjetivos negativos a Antônio Conselheiro como "sicário", "desalmado", "audaz caudilho" e referências aos sertanejos como "bandidos". Além disso, ocorre a publicação do boato de que os canudenses contavam como um instrutor italiano, fato que não se tem registro. ${ }^{10}$

Já a Folha do Norte menciona Canudos pela primeira vez na edição do dia 25 de janeiro de 1897 noticiando a retirada das tropas governistas dos arredores do vilarejo. Nesse telegrama Conselheiro e os canudenses não são retratados de forma pejorativa, o que não vamos observar nas publicações seguintes. Como no telegrama publicado no dia 29, onde é relatado que o governo federal mandaria com urgência "grande força para a Bahia, afim de doar combate decisivo aos fanaticos de conselheiro" (FOLHA DO NORTE, 29 jan. 1897, 2); no telegrama reproduzido no dia seguinte, comunica que $016^{\circ}$ batalhão seria enviado para combater a "horda de criminosos que ao mando do faccinora Conselheiro, arrasa os sertões d'aquelle estado" (FOLHA DO NORTE, 30 jan. 1897, 2) e no dia 3 de fevereiro divulga que "Antonio Conselheiro e seus fanaticos constituem um perigo e uma vergonha para a nossa civilisação". Na correspondência os canudenses ainda são caracterizados como "os bandos perigosos de Conselheiro. (FOLHA DO NORTE, 3 fev. 1897, 2).

Conforme Jacob Lima, "a Folha do Norte refletia a opinião pública corrente na capital do país" (LIMA, 2006, 9), o que notamos logo nas primeiras notas sobre o conflito. Assim como A Província do Pará, a Folha reproduz termos pejorativos veiculados na imprensa nacional como "fanáticos" e "bandos perigosos".

Após o fracasso da $3^{a}$ expedição (confirmada oficialmente no dia 8 de março de 1897), tal qual ocorria em diversos órgãos jornalísticos do país, esses periódicos darão maior destaque à guerra. Além dos telegramas, vemos grandes reportagens, que irão mostrar a repercussão da derrota na cidade de Belém. Da mesma forma a partir desse momento os diários irão dedicar colunas para tratar do conflito, com o título Canudos, em suas edições.

A Província do Pará dedica a edição do dia 9 de março a noticiar o insucesso da expedição comandada pelo Coronel Moreira César. Inicia a mesma demonstrando pesar pelo insucesso da expedição, comentando que no dia anterior manteve "seu estandarte em

\footnotetext{
${ }^{10}$ Segundo Lidiane Pinheiro, muitos boatos eram publicados como fatos reais, devido a pobre estrutura para a circulação e averiguação das notícias. (PINHEIRO, 2005, 8) 


\section{HISTÓRIA \\ O CONFLITO ENTRE OS “FANÁTICOS” E A "POLÍCIA HEROICA": MEMÓRIAS DE CANUDOS NOS JORNAIS E EM VERSOS DE CORDEL NO PARÁ (1897-1940) \\ Patrícia dos Santos Lieuthier Freitas \& Geraldo Magella de Menezes Neto}

funeral", em consideração aos militares que "cumpriram com o seu dever, morrendo no campo de batalha". Nessa reportagem ainda relaciona o sebastianismo ${ }^{11}$ à ideia de que os canudenses estavam ligados aos monarquistas, dizendo que "Atraz da boçalidade dos estúpidos sertanejos fanáticos está agachada a hydra vesga e faminta do sebastianismo incansavel". (A PROVÍNCIA DO PARÁ, 9 mar. 1897, 1)

Segundo a reportagem "O dia de Hontem", publicada na mesma edição, a derrota da terceira expedição "tornara-se objecto único dos commentarios geraes" na capital paraense. A publicação mostra que o interesse por notícias sobre esse acontecimento foi grande, destacando que "A' porta de nosso edifício havíamos afixado pela manhansinha um boletim recomendando a leitura do numero do dia, mas bem depressa tivemos de o retirar, por ter-se exgottado a nossa edição". (A PROVÍNCIA DO PARÁ, 9 mar. 1897, 1)

Podemos observar ainda a repercussão na cidade através da nota "Apello ao povo paraense" publicada na Folha do Norte que chama os moradores da capital para participar de um meeting ${ }^{12}$ que seria realizado no Largo de Sant'anna. Segundo a publicação, a reunião tinha por objetivo "deliberar sobre os meios de contribuir para a defesa da ordem e das instituitções republicanas, caso periclitem com os successos que se vão desenvolvendo n'aquella parte do paiz" (FOLHA DO NORTE, 9 mar. 1897, 2).

O mesmo jornal publica nesse momento, grandes reportagens tentando entender quem era Antonio Conselheiro, o que ele pregava e que também tenatndo caracterizá-lo fisicamente. Dentre elas, reproduz o relato do padre capuchinho João Evangelista do Monte Marciano, que foi em missão a Canudos, publicado no jornal baiano Correio de Notícias em 1895, na qual o autor descreve Antonio Conselheiro fisicamente vestindo "túnica de azulão", tendo a "cabeça descoberta", "os cabellos crescidos, sem nenhum trato a cahirem sobre os ombros"; "hirsutas barbas grisalhas, mais para brancas"; "olhos fundos" e "o rosto comprido e de uma pallidez quase cadavérica". (MARCIANO apud Folha do Norte, 11 mar. 1897, 1).

Observamos que nesse momento a Folha do Norte e A Província do Pará, seguem a tendência da imprensa nacional de dedicar um espaço maior para discutir o desenrolar do conflito no interior da Bahia, bem como reproduzem e enfatizam a ideia do movimento de Canudos como uma conspiração monarquista contra o regime republicano, passando a imagem dos sertanejos de fanáticos, bandidos, monarquistas. Sugerem também um interesse

\footnotetext{
${ }^{11}$ Crença no retorno do rei português D. Sebastião, desaparecido na Batalha de Alcacer-Quibir em 1578. Segundo Galvão, o termo foi atribuído ao movimento de Canudos por autoridades e jornalistas como sinônimo de monarquismo. (GALVÃO, 2001, p. 107),

${ }^{12}$ Reuniões políticas em locais públicos, atualmente conhecidas como comícios.
} 


\section{HISTÓRIA \\ O CONFLITO ENTRE OS "FANÁTICOS” E A "POLÍCIA HEROICA": MEMÓRIAS DE CANUDOS NOS JORNAIS E EM VERSOS DE CORDEL NO PARÁ (1897-1940) \\ Patrícia dos Santos Lieuthier Freitas \& Geraldo Magella de Menezes Neto}

por parte dos moradores de Belém em saber dos últimos acontecimentos da guerra e de quem se tratava Conselheiro.

Conforme Monteiro "tão importante quanto a participação do regimento paraense em Canudos, indubitavelmente, foi a participação ativa que a imprensa teve nos eventos ocorridos no sertão baiano, dando-Ihe relevo e coloração" (MONTEIRO, 2011, 80). Segundo William Gaia Farias, a integração das tropas paraenses ao efetivo que iria participar como reforço na $4^{\mathrm{a}}$ expedição era uma forma de "demonstrar sua devoção à causa e à integração nacional e seu posicionamento contrário a qualquer atitude separatista" (FARIAS, 2010, 64). A Folha do Norte e A Província do Pará ressaltam isso em várias de suas reportagens a respeito da participação da Polícia Militar do Pará no conflito, que consideram como um dever patriótico e atribuem uma imagem heroica às tropas paraenses.

Observamos essa exaltação das tropas paraenses na coluna "Brumas", onde o autor (não identificado) exalta o regime republicano e afirma que os combatentes iriam se "bater pelo bem commum" Ainda caracteriza Conselheiro como "enlouquecido heróe que não é bem um duende, nem perfeitamente um ser humano!". O autor ainda apresenta a imagem dos soldados paraenses como guerreiros que irão honrar e "proteger" o seu estado, afirma que as "lágrimas" pela partida deles, se transformariam "em globulos, e estes por sua vez transformarão teus filhos em titans, em tua defeza, solo generoso, em tua honra terra de Gurjão". (A Província do Pará, 5 ago. 1897, 1).

Esses periódicos cobrirão os preparativos e as cerimônias ocorridas antes e no dia do embarque para a Bahia no dia 5 de agosto de 1897. Na edição do dia 6 de agosto A Província reporta a celebração ocorrida no dia do embarque. Segundo a reportagem, esta "foi uma cerimônia imponentissima" (A PROVÍNCIA DO PARÁ, 6 ago. 1897, 1) e chamou a atenção dos moradores da capital paraense. O repórter conta que:

\footnotetext{
Pouco antes do meio dia todas as forças que fazem parte da expedição achavam-se reunidas à Praça da República, na avenida da liberdade, onde havia, desde muito tempo antes, enorme e desusada agglomeração de povo. Ahí o digno commandante do regimento militar, Sr. Coronel Sotero de Menezes, depois de algumas manobras effectuadas pela força, deu ordem de marcha desfilando esta em direcção ao trapiche da Companhia Lloyd Brasileiro. (A PROVÍNCIA DO PARÁ, 6 ago. 1897, 1).
}

Os jornais também elogiam a atuação da brigada militar paraense nas últimas batalhas da campanha. A Folha comenta a respeito do combate do dia 25 de setembro em duas reportagens: na reportagem "Canudos - Dous grandes combates", na edição do dia 27 de setembro de 1897, onde é relatado que as tropas comandadas pelo coronel Sotero de REHR| Dourados, MS | v. 12 | n. 23| p. 313- 336 jan. / jun. 2018 


\section{HISTÓRIA \\ O CONFLITO ENTRE OS “FANÁTICOS” E A "POLÍCIA HEROICA": MEMÓRIAS DE CANUDOS NOS JORNAIS E EM VERSOS DE CORDEL NO PARÁ (1897-1940) \\ Patrícia dos Santos Lieuthier Freitas \& Geraldo Magella de Menezes Neto}

Menezes tinham ocupado "a estrada do Auauá tomando também outras posições à margem do Rio Vasa-Barris e cortando todas as communicações com o inimigo" (FOLHA DO NORTE, 27 set. 1897, 2); e na reportagem "Feitos da Polícia da Amazônia", veiculada em $1^{\circ}$ de outubro de 1897, em que é publicado um telegrama enviado por Sotero de Menezes ao governador Paes de Carvalho, onde o comandante comenta o ocorrido com mais detalhes. O coronel parabeniza aos que lutaram e deixaram "o pavilhão do Pará hasteado no centro de Canudos", mencionando os soldados e oficiais feridos e/ou mortos na batalha e elogiando a atuação do tenente-coronel Fontoura e dos médicos. Para ele "todo o pessoal cumprio o seu dever". (FOLHA DO NORTE, 1 out. 1897, 2).

A Província comenta sobre o recebimento dessas informações também na edição de $1^{\circ}$ de outubro de 1897, compartilhando o mesmo discurso da Folha; demonstra pesar pelo falecimento dos soldados e ressalta que: "O contigente paraense houveram-se com muita coragem, sendo também dignos de nota os relevantes serviços prestados pelos médicos" (A PROVÍNCIA DO PARÁ, 1 out. 1897, 3). Já a atuação no combate do dia $1^{\circ}$ de outubro (a batalha final, que segue até o dia 5) é relatada em um telegrama publicado no dia 15 de outubro. O autor conta que naquele momento, após um discurso do coronel Sotero de Menezes para os combatentes estes foram tomados por "valentia" e "ao fim de meia hora estavam tomadas cerca de 90 casas de jagunço, sendo heroicamente conservadas as posições". (A PROVÍNCIA DO PARÁ, 15 out. 1897, 3).

A Folha do Norte e A Província do Pará irão publicar grandes reportagens sobre o retorno das tropas no dia 4 de Novembro de 1897. A Folha em "Canudos: O regresso dos bravos" relata a organização dos festejos para a recepção dos soldados em Belém. O autor começa a matéria declarando que receberiam naquele dia, "com legitimo orgulho", "o punhado de bravos que há mezes d'aqui saio, para desaggravar a honra nacional e consolidar a Republica". (FOLHA DO NORTE, 4 nov. 1897, 2).

A reportagem comenta que as ruas da capital paraense estavam decoradas em homenagem ao regimento. Uma das que se destacavam pela ornamentação era a Santo Antonio que ostentava "vistosa ornamentação de bandeiras, festões, galhardetes, palmeiras, folhagens, serpentinas, etc". Além disso, segundo o repórter ocorreu um "embandeiramento geral das casas". (FOLHA DO NORTE, 4 nov. 1897, 2).

$\mathrm{Na}$ edição dia seguinte esses diários relatam a cerimônia e as festas ocorridas após o desembarque do regimento na capital paraense, nas reportagens "Canudos: a chegada da milícia paraense, o desembarque, alta demonstração de apreço, o enthusiasmo popular", da Folha do Norte, e "Regresso dos bravos: a chegada dos paraenses", de A Província do Pará. 


\section{HISTÓRIA \\ O CONFLITO ENTRE OS “FANÁTICOS” E A "POLÍCIA HEROICA": MEMÓRIAS DE CANUDOS NOS JORNAIS E EM VERSOS DE CORDEL NO PARÁ (1897-1940) \\ Patrícia dos Santos Lieuthier Freitas \& Geraldo Magella de Menezes Neto}

Os jornais sempre exaltam a atuação da brigada militar no sertão baiano e passam a ideia de que os moradores desta capital estavam agradecidos pelas tropas terem ido lutar em "defesa da República". E assim como nos relatos das cerimônias organizadas para o embarque, os jornalistas dos dois periódicos ressaltam a participação popular nas celebrações.

Para o repórter de A Província as "duas terças partes dos habitantes de Belém" que assistiam a solenidade expressavam "sinceridade de sentimentos patrióticos" e gratidão e que as manifestações em homenagem às tropas "estiveram na justa altura dos serviços prestados pelo regimento". (A PROVÍNCIA DO PARÁ, 5 nov. 1897, 1)

$\mathrm{Na}$ notícia da Folha do Norte é relatado que "a’s 6 horas da manhã girândolas de foguetes e tiros de morteiros, amiudadamente repetidos annunciavam ao povo que o Planeta ${ }^{13}$ demandava a barra do porto de Belém" (FOLHA DO NORTE, 5 nov. 1897, 2). Segundo o repórter, desde essa hora "desusado movimento notava-se em as ruas principaes da cidade". Ele conta que o povo a cada momento "ia avolumando em massa no Boulevard da República" (atual Boulevard Castilhos França), da mesma forma tinha uma "multidão nas proximidades do trapiche da companhia Amazonas". Ainda conta que "em todas as janellas numerosissimas familias aguardavam a passagem das tropas; havia gente até nas mangueiras marginaes do boulevard". (FOLHA DO NORTE, 5 nov. 1897, 2).

A reportagem da Província, além de descrever a ornamentação das casas e ruas da cidade, conta que " $A$ ' noite houve illuminações nos prédios públicos e, na maioria dos prédios reuniões, bailes, etc."

Além disso, as matérias mostram que as celebrações pelo retorno dos combatentes paraenses mudaram a rotina da cidade. Como podemos ver na reportagem "Canudos: o regresso dos bravos" da Folha do Norte, onde também divulgam um decreto em que o governador Paes de Carvalho determinava feriado para as repartições públicas do Estado nos dias 4, 5 e 6 de novembro de 1897, segundo declarava em documento:

com o fim de dar maior solemnidade aos festejos que devem ser feitos para a recepção do Regimento Militar em seu regresso dos sertões da Bahia, onde houve-se com bravura e brilhantismo em defesa das instituições republicanas. (FOLHA DO NORTE, 4 nov. 1897, 2)

Segundo a reportagem de A Província até "o commercio, quer nacional, quer extrangeiro, também se associou a's festas, não abrindo seus estabelecimentos". (A PROVÍNCIA DO PARÁ, 5 nov. 1897, 1). Um exemplo da importância do significado do retorno

\footnotetext{
${ }^{13}$ Embarcação na qual as forças policiais paraenses retornaram a Belém.
} 


\section{HISTÓRIA \\ O CONFLITO ENTRE OS “FANÁTICOS” E A "POLÍCIA HEROICA": MEMÓRIAS DE CANUDOS NOS JORNAIS E EM VERSOS DE CORDEL NO PARÁ (1897-1940) \\ Patrícia dos Santos Lieuthier Freitas \& Geraldo Magella de Menezes Neto}

das tropas para Belém é que nesse dia o governo estadual decretou feriado para celebrar a vitória em Canudos.

Podemos ver que a Guerra de Canudos repercutiu bastante nos jornais paraenses Folha do Norte e A Província do Pará. Esses órgãos jornalísticos concordam com o discurso corrente na imprensa nacional de que Canudos representava um perigo à nação e à República e reproduziam a mesma imagem depreciativa sobre Antonio Conselheiro e seus seguidores propagada nos principais noticiários do país. Em suas reportagens atribuem a eles adjetivos como: "sicário", "facínora, "desalmando", "fanáticos", "bandidos", "sebastianistas" "bandos perigosos", entre outros. Apesar de serem ligados a grupos políticos "inimigos", os jornais concordam quanto à repressão ao arraial, bem como justificam e apoiam a participação das tropas da Polícia Militar no conflito, sempre exaltando-as como heroicas, como defensoras de seu estado, da pátria e do regime republicano.

Através desses periódicos podemos observar a repercussão do conflito em Belém, como o meeting ocorrido após a morte do coronel Moreira Cesar; as celebrações na ocasião do embarque e do retorno dos soldados paraenses, sendo ressaltada a participação popular nesses momentos. Além disso, o fato dos estabelecimentos comerciais não abrirem durante os festejos, mostra que esta contenda em alguns momentos alterou o cotidiano na cidade de Belém.

Canudos: Memória e poesia popular

Quando falamos da Guerra de Canudos, é preciso comentar da importância do livro Os sertões (1902) de Euclides da Cunha ${ }^{14}$ para a memória sobre o episódio. Conforme Antonio Sá, a obra se tornou paradigma para a historiografia canudeana e continua sendo o principal veículo pelo qual a maioria dos brasileiros conhece o fato. (SÁ, 2006, 120). Da mesma forma o autor aponta para a questão da tradição oral na construção da memória sobre o conflito, para ele a tradição oral "é fundamental para a produção de narrativas faladas ou escritas sobre o passado", pois por meio da palavra cantada e falada é transmitida através de gerações "a soma de conhecimento sobre a natureza e a vida, os valores morais da sociedade, a concepção religiosa do mundo, o relato dos eventos passados e contemporâneos, a lenda, a poesia" (SÁ, 2006, 168).

\footnotetext{
${ }^{14}$ Engenheiro e jornalista. Participou da $4^{\text {a }}$ expedição da campanha como correspondente do jornal $O$ Estado de São Paulo. Sua obra Os Sertões é influenciada por teorias como Determinismo Geográfico e Darwinismo Social e sustenta "uma diversidade de representações sobre o sertanejo e seu mundo: ora ele é admirado como forte enfrentando as condições do meio, ora é desprezado como um ser ignorante, perigoso, rebelde, jagunço bandido, místico, vivendo numa terra amaldiçoada". (SILVA, 2001, 49).
} 


\section{HISTÓRIA \\ O CONFLITO ENTRE OS "FANÁTICOS" E A "POLÍCIA HEROICA": MEMÓRIAS DE CANUDOS NOS JORNAIS E EM VERSOS DE CORDEL NO PARÁ (1897-1940) \\ Patrícia dos Santos Lieuthier Freitas \& Geraldo Magella de Menezes Neto}

Nesse sentido, Antonio Sá considera a literatura de cordel $^{15}$ "fundamental para a constituição da tradição oral nordestina, seja para o caso do cangaço, ou da guerra de Canudos" (SÁ, 2006, 168).

José Calasans mostra que esses poemas populares compõem um ciclo folclórico ${ }^{16} \mathrm{em}$ torno da figura de Antonio Conselheiro. $O$ autor divide esse ciclo em três fases: a primeira é a fase do apostolado; com versos tratando das ideias e da peregrinação do beato; a segunda é a fase da campanha, onde ele deixa de ser considerado o único herói dos poemas e cantigas, passando também a apresentar militares como heróis, como o coronel Moreira César e a terceira e ultima é a fase do messianismo conselheirista; que começa após a morte de Conselheiro, onde os escritos expressam a crença na ressurreição do mesmo. (CALASANS, 2002, 15).

Mark Curran conta que a Guerra de Canudos e a história de Conselheiro são reconhecidas como um dos primeiros grandes eventos registrados em Cordel. O autor conta que o poeta-militar João Melchiades Ferreira da Silva, que participou da campanha e escreveu seu relato após a aposentadoria do exército em 1904, "foi o autor de um texto primordial sobre Canudos" (CURRAN, 2003, 44), que serviu de protótipo para inúmeras narrativas posteriores baseadas em eventos. Em seus versos considera as tropas federais como heroicas e avalia a guerra como uma batalha entre o bem e mal, e tornou-se modelo para a crônica cordeliana dos anos seguintes (CURRAN, 2003, 53).

Vários folhetos de cordel retrataram o conflito de Canudos $^{17}$, não apenas no Nordeste. No estado do Pará, por exemplo, já bem depois do evento, no ano de 1940, é publicado pela

\footnotetext{
${ }^{15} \mathrm{O}$ cordel é uma poesia em forma de versos rimados, com temáticas variadas, Márcia Abreu afirma que para adequar-se à 'estrutura oficial' da literatura de cordel, um texto deve ser escrito "em versos setessilábicos ou em décimas, com estrofes de seis, sete ou dez versos". Deve seguir um "esquema fixo de rimas e deve apresentar um conteúdo linear e claramente organizado". Deve, portanto, ter "rima, métrica e oração." (ABREU, 1999, 119). O principal suporte do cordel é o 'folheto', que é impresso em papel pardo, de má qualidade, medindo de 15 a $17 \times 11 \mathrm{~cm}$. Nas capas se estampam o nome do autor, os títulos dos poemas, o nome da tipografia impressora e seu endereço. Algumas vezes, a data de publicação, o preço, a indicação do local de venda (TERRA, 1983, 23), além de uma imagem representando o tema da história. Em relação ao número de páginas, Joseph Luyten aponta que o folheto é feito a partir de uma folha tipo sulfite dobrada em quatro. Por isso, o número de páginas da literatura de cordel deve ser múltiplo de oito, já que cada folha sulfite dobrada em quatro dá possibilidade para oito páginas impressas. (LUYTEN, 2005, 45).

${ }_{16}$ Conforme Calasans, o ciclo folclórico consiste em "um conjunto de lendas, estórias, milagres, profecias, cantigas, simples versos gerais, ditos populares concernentes a Antonio Conselheiro e a Canudos". (CALASANS, 2002, 15).

${ }^{17}$ Podemos citar ainda como exemplo os folhetos: A Guerra de Canudos no sertão da Bahia de João de Souza Cunegundes; Sangue de irmãos de José Aras; Antonio Conselheiro o Santo Guerreiro de Canudos de Rodolfo Coelho Cavalcanti. (CALASANS, 1984, 3), e Antonio Conselheiro e o cangaceiro Romão de Felipe Saboia Dilla.
} 


\section{HISTÓRIA \\ O CONFLITO ENTRE OS “FANÁTICOS” E A "POLÍCIA HEROICA": MEMÓRIAS DE CANUDOS NOS JORNAIS E EM VERSOS DE CORDEL NO PARÁ (1897-1940) \\ Patrícia dos Santos Lieuthier Freitas \& Geraldo Magella de Menezes Neto}

editora Guajarina o folheto História de Antonio Conselheiro (Campanha de Canudos, narração completa), de Arinos de Belém. Antes de analisar o folheto sobre Canudos escrito pelo poeta paraense Arinos de Belém, precisamos comentar brevemente sobre a chegada desse tipo de literatura na Amazônia.

Segundo Vicente Salles, na segunda metade do século XIX, devido ao apogeu do comércio da borracha e a valorização deste produto no mercado internacional, a Amazônia atraiu muitos migrantes nordestinos, que também fugiam das secas em sua região. ${ }^{18}$ Salles comenta que, dentre esses migrantes, "cantadores violeiros e poetas nordestinos se aventuraram nas plagas amazônicas, tangidos do Ceará, Rio Grande do Norte, Paraíba, Piauí, Alagoas, Pernambuco" (SALLES, 1985, 93). Essa migração gerou um desenvolvimento do mercado consumidor de poesia, estimulando também a produção e o consumo da literatura de cordel. (SALLES, 1985, 93). Salles ainda mostra que a Editora Guajarina, fundada em 1914 por Francisco Lopes, teve um papel importante na difusão dos folhetos, embora a tipografia não se dedicasse exclusivamente a publicar a poesia popular, se especializou na publicação dos folhetos e foi "a mais importante editora do extremo norte" (SALLES, 1985, 152).

Arinos de Belém, pseudônimo ${ }^{19}$ de José Esteves, foi um dos importantes poetas cordelistas paraenses que publicaram pela editora Guajarina. Segundo Vicente Salles, o poeta leu intensamente cordéis nordestinos e produziu vários folhetos com temáticas nordestinas, entre estes História de Antonio Conselheiro (Campanha de Canudos, narração completa) publicado, em 1940. (SALLES, 1985, 185). Calasans, que comenta sobre o folheto na obra Canudos na literatura de cordel, acredita que o poeta tenha se interessado pelo tema devido à participação da Policia Militar do Pará no conflito (CALASANS, 1984, 9); já Vicente Salles cogita que o folheto pode ter sido inspirado no livro $A$ Quarta expedição contra Canudos de A. Constantino Nery, publicado em Belém em 1898.

Além dessa leitura, é interessante enumerar obras sobre a campanha que foram publicadas até $1940 \mathrm{com}$ as quais o autor pode ter tido contato. Podemos citar: Última expedição a Canudos (1898) e Acidentes de Guerra de Dantas Barreto (1914), Os Jagunços de Afonso Arinos (1898), Os Sertões de Euclides da Cunha (1902), O rei dos Jagunços de

${ }^{18}$ Conforme mostra Franciane Gama Lacerda os momentos de socialização eram fundamentais na vida desses migrantes. Segundo a autora "por meio da música e dança se evocava uma memória do passado e fortaleciam-se, sem dúvida, os laços identitários com os lugares de origem" (LACERDA, 2010,368 ).

${ }^{19}$ Nome criado por um autor com objetivo de ocultar seu nome verdadeiro. 


\section{HISTÓRIA \\ O CONFLITO ENTRE OS “FANÁTICOS” E A "POLÍCIA HEROICA": MEMÓRIAS DE CANUDOS NOS JORNAIS E EM VERSOS DE CORDEL NO PARÁ (1897-1940) \\ Patrícia dos Santos Lieuthier Freitas \& Geraldo Magella de Menezes Neto}

Manuel Benício (dentre outros). (CALASANS, 1958). No caso das obras que falam da participação das tropas paraenses publicadas no Pará, podemos citar os trabalhos escritos por Arthur Vianna, um em 1899 (que não foi encontrado) e uma série de reportagens escritas para o Jornal do Comercio no ano de 1904 sob o título "Diário do regimento militar do Pará na Guerra de Canudos" (depois publicada por Clovis Moraes Rego em Contribuição à História da cadeira $n^{\circ} 8$ do Instituto Histórico e geográfico do Pará em 1971), e o livro de Orvácio Deolindo da Cunha Marreca A milícia paraense e sua heroica atuação na Guerra de Canudos publicado em 1937. (GOMES FILHO, 2008; FARIAS; VILHENA, 2015).

Além disso, temos que considerar que os jornais podem servir de fonte para os poetas cordelistas, "principalmente nos chamados 'folhetos de acontecido', aqueles que tratam dos 'últimos acontecimentos', desde temas locais como crimes, acidentes, mortes de políticos importantes, até os de âmbito nacional e internacional, como revoluções e guerras" (MENEZES NETO, 2011, 54). Dessa forma, além de cordéis nordestinos e obras publicadas sobre a Guerra de Canudos, Arinos de Belém também pode ter tido contato com reportagens a respeito do conflito.

O folheto História de Antonio Conselheiro (Campanha de Canudos, narração completa) possui 35 páginas, sendo seus versos em sextilhas. Podemos supor que ao dizer que trata-se de uma "narração completa", o folheto seja uma versão completa de duas ou mais partes da história que foram publicadas separadamente, algo comum na estratégia editorial da Guajarina. O mesmo Arinos de Belém publicou com grande sucesso de vendas o folheto O crime da Praça da República, que foi dividido em duas partes e depois saiu uma edição completa reunindo toda a história. (MENEZES NETO, 2011).

O poeta paraense inicia o folheto mencionando a origem cearense de Conselheiro contando que: "em Quixeramobim/ tinha casa de negóciol pois o labor tudo vence". (BELÉM, 1940, p. 1). Conta que após o casamento de uma das irmãs, Conselheiro muda-se para Ipu "onde muito trabalhou". (BELÉM, 1940, 2). Nesse momento de sua narração, nota-se que o autor mostra certo respeito por Antonio Vicente Maciel, dando a entender que ele era trabalhador, o que difere das reportagens dos diários paraenses da época do conflito, que reproduzem sua imagem como de "bandido", "facínora", "fanático", "enlouquecido".

Se o cordelista tem uma visão positiva sobre o homem Antonio Vicente Mendes Maciel como trabalhador, o mesmo não podemos dizer sobre a imagem que ele tem do "Bom Jesus Conselheiro", quando relata sua fase de peregrinação e da instalação do mesmo e de seus seguidores no Belo Monte, que será pejorativa. Segundo o autor o abandono de Antonio 


\title{
HISTÓRIA \\ O CONFLITO ENTRE OS "FANÁTICOS" E A "POLÍCIA HEROICA": MEMÓRIAS DE CANUDOS NOS JORNAIS E EM VERSOS DE CORDEL NO PARÁ (1897-1940) \\ Patrícia dos Santos Lieuthier Freitas \& Geraldo Magella de Menezes Neto
}

Conselheiro pela primeira esposa seria a causa para ele "nos sertões se embrenhar" (BELÉM, 1940, 2). Nesse momento relata que o beato:

\author{
Penetrou pela Bahia \\ em traje penitente \\ deixou crescer o cabelo \\ que nunca mais viu um pente \\ e as unhas também cresceram \\ ficou mesmo repelente. (BELÉM, 1940, 2).
}

Conforme Menezes Neto, nos folhetos sobre crime publicados pela Guajarina, os poeta atribuíam aos criminosos características que tendiam a desumanizá-los. (MENEZES NETO, 2011, 63). Podemos observar essa estratégia poética na descrição física feita de Conselheiro por Arinos de Belém em vários versos, quando faz referência, por exemplo, à fotografia de Conselheiro tirada por Flávio de Barros ${ }^{20}$, o que nos sugere que ele considerava o beato como "bandido":

\author{
Dêsse Antonio Conselheiro \\ um retrato apareceu \\ Cabelos e barbas compridos \\ com um bicho se pareceu. (BELÉM, 1940, 35).
}

As características físicas descritas pelo poeta são próximas das apresentadas no relato do padre capuchinho João Evangelista do Monte Marciano "resgatado" pela Folha do Norte, onde este caracteriza Conselheiro vestindo "túnica de azulão", com "cabellos crescidos, sem nenhum trato a cahirem sobre os ombros"; "hirsutas barbas grisalhas, mais para brancas"; "olhos fundos" e "o rosto comprido e de uma pallidez quase cadavérica" e na caracterização feita na reportagem de $A$ Província como não sendo "um duende, nem perfeitamente um ser humano".

Seguindo a narração da fase da peregrinação, o cordelista afirma que os discursos de Conselheiro "iam anarquizando o sertão" (BELÉM, 1940, 4) e que ele pregava uma doutrina de rebelião: fanatizando os jagunços/ até contra a religião" (BELÉM, 1940, 4).

Quando relata o estabelecimento dos sertanejos em Canudos, Arinos de Belém declara que o arraial "era refugio de malvada cabroeira" (BELÉM, 1940, 5), "abrigo de muitos

\footnotetext{
${ }^{20}$ Fotógrafo que acompanhou a $4^{\mathrm{a}}$ expedição, retratando oficiais de alguns batalhões que fizeram parte da campanha, dos canudenses prisioneiros, do cadáver de Antonio Conselheiro. Fazendo uma exposição das mesmas em dezembro de 1897 (SANTOS, 2014, p. 26). 


\section{HISTÓRIA \\ O CONFLITO ENTRE OS "FANÁTICOS" E A "POLÍCIA HEROICA": MEMÓRIAS DE CANUDOS NOS JORNAIS E EM VERSOS DE CORDEL NO PARÁ (1897-1940) \\ Patrícia dos Santos Lieuthier Freitas \& Geraldo Magella de Menezes Neto}

cabras safados" (BELÉM, 1940, p. 5) e que "os crimes num só dia, até passavam de cem" (BELÉM, 1940, 6). O autor apresenta praticamente a mesma imagem dos canudenses como "os bandos perigosos de Conselheiro", "assaltantes de fazendas", que era propagada nesses noticiários na época da guerra.

O poeta comenta quando as tropas da Polícia militar de São Paulo, Amazonas e Pará são convocadas durante a quarta expedição, que:

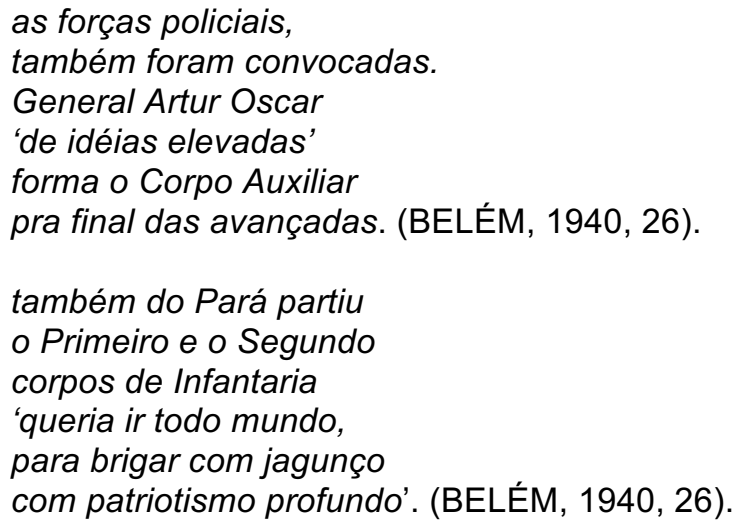

Assim como as matérias publicadas na Folha e na Província, o autor irá exaltar a participação do regimento paraense, como vemos nos versos.

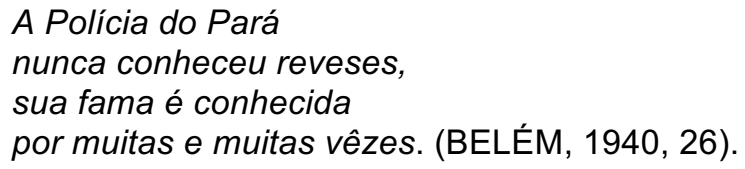

Seu apreço pelas forças policiais do Pará é demonstrado ainda mais durante a descrição do combate de 25 de setembro de 1897, que para ele foi "a parte mais importante da confusão de canudos" (BELÉM, 1940, 28) e afirma que a atuação na batalha demonstrava a bravura das tropas e lhes renderia fama. Descreve o momento em que as tropas conseguem adentrar em Canudos nos versos:

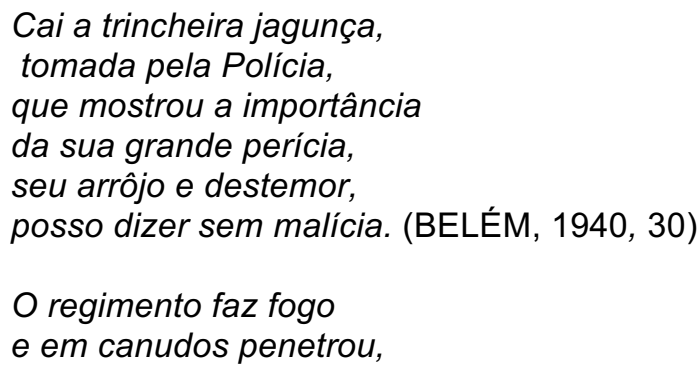




\title{
HISTÓRIA \\ O CONFLITO ENTRE OS "FANÁTICOS" E A "POLÍCIA HEROICA": MEMÓRIAS DE CANUDOS NOS JORNAIS E EM VERSOS DE CORDEL NO PARÁ (1897-1940) \\ Patrícia dos Santos Lieuthier Freitas \& Geraldo Magella de Menezes Neto \\ e mais de duzentas casas \\ a Polícia conquistou, \\ boas posições ganharam \\ que o jagunço abandonou. (BELÉM, 1940, 31)
}

Nos versos finais, quando relata os últimos dias da campanha e a vitória das tropas legalistas, Arinos de Belém narra que:

\author{
A $1^{\circ}$ de outubro de nôvo participou \\ de outro ataque a Canudos \\ que novamente chocou \\ e arrasado de vez \\ Canudos capitulou. (BELÉM, 1940, 34).
}

Para o poeta, devido a participação do Regimento paraense no conflito:

\author{
a Polícia do Pará \\ tem a fama da vitória \\ que nunca mais morrerá, \\ e o povo paraense \\ orgulhoso a guardará. (BELÉM, 194, 34).
}

E conclui o folheto, conforme comenta José Calasans, "expressando seu anticonselheirismo" (CALASANS, 1984, 10):

\author{
Na Bahia o fanatismo \\ caro ao Govêrno custou, \\ e Antonio Conselheiro \\ nunca em luta se mostrou \\ e conforme alguém já disse \\ o Diabo o carregou. (BELÉM, 1940, 36).
}

Quando trata da participação das tropas paraenses, o poeta ainda tem a mesma visão heroica da participação delas na guerra, bem como a de que isto era motivo de orgulho e gratidão para os moradores da capital paraense, assim como as reportagens de A Província do Pará e Folha do Norte apresentam na época do conflito, que atribuem adjetivos como "titãs", "bravos", "corajosos".

Podemos relacionar a continuidade dessa visão com o que Michael Pollak aponta em relação ao dito e ao não-dito nas memórias das sociedades:

A fronteira entre o dizível e o indizível, o confessável e o inconfessável, separa, em nossos exemplos, uma memória coletiva subterrânea da sociedade civil dominada ou de grupos específicos, de uma memória coletiva 


\section{HISTÓRIA \\ O CONFLITO ENTRE OS “FANÁTICOS" E A "POLÍCIA HEROICA": MEMÓRIAS DE CANUDOS NOS JORNAIS E EM VERSOS DE CORDEL NO PARÁ (1897-1940) \\ Patrícia dos Santos Lieuthier Freitas \& Geraldo Magella de Menezes Neto \\ organizada que resume a imagem que uma sociedade majoritária ou o Estado desejam passar e impor. (POLLAK, 1989, p. 8).}

A imagem positiva da participação das tropas paraenses no conflito de Canudos foi construída e reelaborada pelos interesses dos governantes, que desejavam perpetuar a memória dos "bravos e corajosos" soldados. Os mesmos interesses também almejaram perpetuar uma imagem negativa de Antonio Conselheiro, por ser considerado pelas elites republicanas como um mau exemplo para a sociedade. Essa memória, por outro lado, omite os excessos cometidos pelas tropas do governo contra os canudenses.

Observamos que Arinos de Belém ao propor sua "narração completa" da história de Antônio Conselheiro e da Guerra de Canudos, apresenta a continuidade de uma visão pejorativa sobre o "Bom Jesus Conselheiro" e dos Canudenses. Também continua a passar a imagem de uma atuação heroica da Polícia Militar do Pará. Entretanto podemos notar uma mudança em relação à visão que ele tem de Conselheiro antes da peregrinação e de estabelecimento e de seus seguidores no "Belo Monte", que será positiva (em certo sentido, respeitosa), considerando-o como um homem trabalhador.

\section{Considerações Finais}

A guerra no Belo Monte foi um grande evento na imprensa nacional, nesse sentido é natural que os jornais paraenses repercutissem as notícias do conflito. Conforme Expedito Lima "no Pará, os periódicos foram unânimes em apoiar a expedição". (LIMA, 2006, 22). Desta forma A Província do Pará e a Folha do Norte, mesmo estando relacionados a grupos políticos "inimigos" concordam quanto a campanha contra Canudos. Absorvem e propagam a mesma opinião corrente nos jornais do país de que os sertanejos representavam perigo à pátria e ao recente regime republicano, passando a imagem de Conselheiro como "louco", "sicário" e seus seguidores como "fanáticos", "bandidos", "monarquistas".

Os noticiários apoiam e justificam a participação das tropas da Polícia Militar do Pará na contenda, considerando os combatentes como heróis, "bravos", defensores da República e de seu estado. Também enfatizam a participação popular nas celebrações que antecedem a partida para a Bahia e nos festejos ocorridos quando o Regimento retorna à capital paraense, passando a ideia de que a população de Belém apoiava a participação das mesmas na guerra no interior da Bahia.

Passados 40 anos do fim do conflito o poeta Arinos de Belém se propõe a contar a história de Antônio Conselheiro. O poeta ainda apresenta uma memória de Canudos como um "reduto de bandidos", "de fanáticos" e das tropas como heroicas, "dignas de honra e 


\section{HISTÓRIA \\ O CONFLITO ENTRE OS “FANÁTICOS” E A "POLÍCIA HEROICA": MEMÓRIAS DE CANUDOS NOS JORNAIS E EM VERSOS DE CORDEL NO PARÁ (1897-1940) \\ Patrícia dos Santos Lieuthier Freitas \& Geraldo Magella de Menezes Neto}

orgulho", um discurso bem próximo da imagem propagada Pela A Província do Pará e Folha do Norte em 1897. Pierre Nora mostra que a memória pode passar por modificações (NORA, 1993, 9); o que podemos observar na visão do cordelista no inicio do folheto, onde apresenta um "Antonio Vicente Mendes Maciel" como chefe de família, trabalhador; diferente do "Antonio Conselheiro", que ele retrata como "bandido", "louco", que "fanatizava" seus seguidores.

É possível que a memória que o autor tem sobre Canudos seja fruto de leituras de reportagens de jornais (ou pode até mesmo ter entrado em contato com notícias da época), dos cordéis que ele pode ter lido, que podem ter Ihe apresentado uma "memória pejorativa" e de obras que tratavam os sertanejos de forma depreciativa. Assim, entendemos que comparar as reportagens sobre Canudos nos jornais com os versos sobre o conflito em cordel, pode nos revelar múltiplas memórias sobre o evento de Canudos, memórias que apresentam permanências e continuidades com o tempo e que, conforme aponta Leonardo Leite, geram interpretações que podem variar "dependendo das intenções políticas e ideológicas de quem se propôs a rememorar esse acontecimento tão significativo da história do nosso país" (LEITE, 2010, 1). É possível que outras memórias sobre Canudos tenham circulado no Pará no tempo do conflito e na época da publicação do folheto de Arinos de Belém, contudo, as versões escolhidas pelos jornais e pelo poeta cordelista nos revelam escolhas e intenções ligadas sobretudo aos vencedores da guerra.

\section{Fontes}

Acervo Vicente Salles - Museu da Universidade Federal do Pará (UFPA)

Folheto de cordel:

BELÉM, Arinos de. História de Antonio Conselheiro (A Campanha de Canudos -Narração Completa). Belém: Guajarina, 1940. 35p.

\section{Seção de Microfilmagem, Biblioteca Pública Arthur Vianna - Fundação Cultural do Pará (CENTUR)}

Jornais:

\section{A Província do Pará}

Telegrammas: Rio, 10. A Província do Pará, Belém, p. 2, 12 jan. 1897

Telegrammas: Bahia, 27 de janeiro. A Província do Pará, Belém, p. 2, 29 jan. 1897.

Telegrammas: Bahia, 30 de janeiro. A Província do Pará, Belém, p. 2, 31 jan. 1897.

"9 de março". A Província do Pará, Belém, p. 1, 9 mar. 1897.

O dia de hontem. A Província do Pará, Belém, p. 1, 9 mar. 1897. 


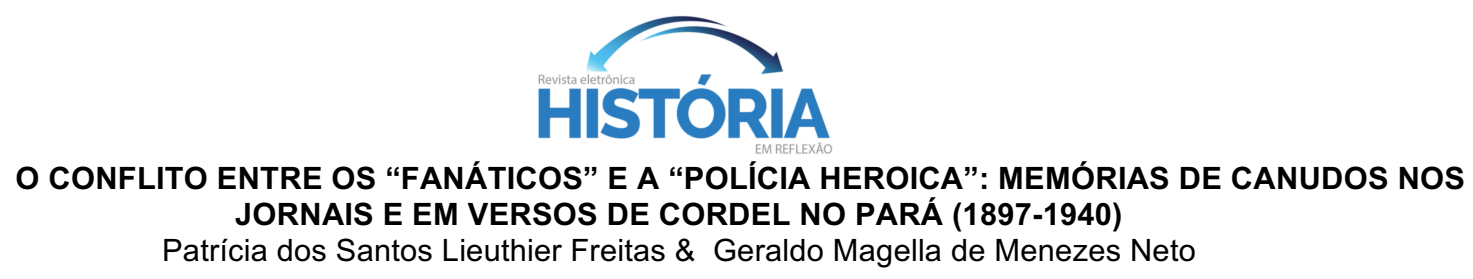

Patrícia dos Santos Lieuthier Freitas \& Geraldo Magella de Menezes Neto

"Brumas". A Província do Pará, Belém, p. 1, 5 ago. 1897.

Canudos. A Província do Pará, p. 1, Belém, 6 ago. 1897.

Canudos. A Província do Pará, Belém, p. 3, 1 out. 1897.

Canudos. A Província do Pará, Belém, p. 3, 15 out. 1897.

Regresso dos bravos: a chegada dos paraenses. A Província do Pará, Belém, p. 1, 5 nov. 1897.

Folha do Norte

Nossos Telegrammas: Rio de janeiro, 27. Folha do Norte, Belém, p. 2, 29 jan. 1897.

Nossos Telegrammas: Rio, 28 de fevereiro. Folha do Norte, Belém, p. 2, 30 jan. 1897.

Nossos Telegrammas: Rio, 1 de fevereiro. Folha do Norte, Belém, p. 2, 3 fev. 1897.

MARCIANO, João Evangelista do Monte. Antonio Conselheiro: A vida em Canudos. Folha do Norte, Belém, p. 1, 11 mar. 1897.

Apello ao povo paraense. Folha do Norte, Belém, p. 2, 9 mar. 1897.

Canudos: Dous grandes combates. Folha do Norte, Belém, p. 2, 27 set. 1897.

Feitos da Polícia da Amazônia. Folha do Norte, p. 2, 1 out. 1897

Canudos: O regresso dos bravos. Folha do Norte, Belém, p. 2, 4 nov. 1897.

Canudos: a chegada da milícia paraense, o desembarque, alta demonstração de apreço, o enthusiasmo popular. Folha do Norte, Belém, p. 2, 5 nov. 1897.

\section{Referências Bibliográficas:}

ABREU, Márcia. História de cordéis e folhetos. Campinas, SP: Mercado de Letras/Associação de Leitura do Brasil, 1999.

ANDRADE, José Wilson de. A experiência religiosa e sociopolítica de Canudos: aspectos eclesiológicos da comunidade de Antonio Conselheiro. Dissertação (Mestrado). Instituto Santo Inácio. Belo Horizonte, 2006.

BIBLIOTECA PÚBLICA DO PARÁ. Catálogo Jornais Paraoaras. Belém: Secretaria de Estado e Cultura, Desportos e Turismo, 1985.

CALASANS, José. Subsídios para bibliografia da Campanha de Canudos. In: Arquivos da Universidade da Bahia - Faculdade de Filosofia, n.6. Salvador: Artes Gráficas, 1958.

Canudos na Literatura de Cordel. São Paulo: Ática, 1984.

O Ciclo Folclórico do Bom Jesus Conselheiro: contribuição ao estudo

da Campanha de Canudos. Salvador: EDUFBA, 2002. 


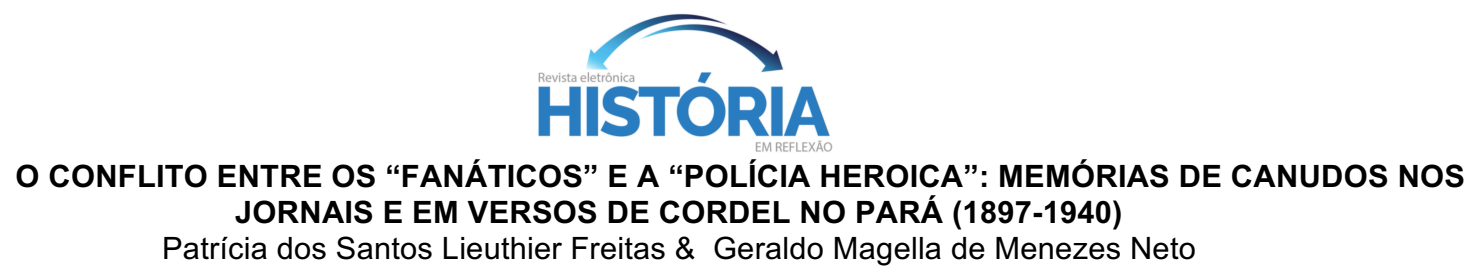

CURRAN, Mark J. Canudos e a República Velha. In: História do Brasil em Cordel. São Paulo: Edusp, 2003. p.35-83.

FARIAS, William Gaia. A construção da República no Pará. Tese (Doutorado). Universidade Federal Fluminense. Rio de Janeiro, 2005.

A brigada militar do Pará na Guerra de Canudos. Revista Alpha.

Patos de Minas, v.11, p. 62-74, 2010.

; VILHENA, Anderson Alexandre Cruz. Como lendários espartanos: a invenção da heroica atuação da polícia paraense em Canudos. Revista Aedos. Porto Alegre, v. 7, n. 17, p. 410-430, 2015.

GALVÃO. Walnice Nogueira. No Calor da Hora: A Guerra de Canudos nos jornais. São Paulo: Editora Ática, 1994.

O Império do Belo Monte: Vida e morte de Canudos. São Paulo: Perseu

Abramo, 2001.

GOMES FILHO, Gregório Ferreira. Sombras da historiografia: Marreca e o Regimento Militar do Pará em Canudos. Examãpaku. Boa Vista, v.1, n.1, p.1-14, 2008.

HERMANN, Jacqueline. Canudos destruído em nome da República: Uma reflexão sobre as causas do massacre de 1897. Tempo. Rio de Janeiro, vol. 2, nº. 3, p. 81-105, 1996.

LACERDA, Franciane Gama. Imprensa e Poesia de Cordel no Pará nas primeiras décadas do século XX. In: XIX Encontro Regional da Seção São Paulo da ANPUH, 2008, São Paulo. Anais - XIX Encontro Regional de História: Poder, violência e exclusão. São Paulo: ANPUH/FAPESP, 2008, v. 1. p. 1-11.

Migrantes cearenses no Pará: faces da sobrevivência

(1889-1916). Belém: Ed. Açaí/Programa de Pós-Graduação em História Social da Amazônia (UFPA)/Centro de Memória da Amazônia (UFPA), 2010.

LEITE, Leonardo Guimarães. Canudos em Debate: A memória como espaço de disputa. In: I Encontro de História do CAHL. Centro de Artes, Humanidades e Letras, Quarteirão Leite Alves, Cachoeira-BA, 18 a 21 de outubro de 2010.

LIMA, Jacob Expedito P. de. Expedição paraense em canudos e o republicanismo de 1897. Monografia (Bacharelado e Licenciatura Plena em História). Universidade Federal do Pará. Belém, 2006.

LUYTEN, Joseph. O que é literatura de cordel. São Paulo: Brasiliense, 2005.

MENEZES NETO, Geraldo Magella de. A notícia em versos: relações entre jornais e folhetos de cordel no Pará na primeira metade do século XX. Fronteiras. Florianópolis, v. 19, p. 5372, 2011. 


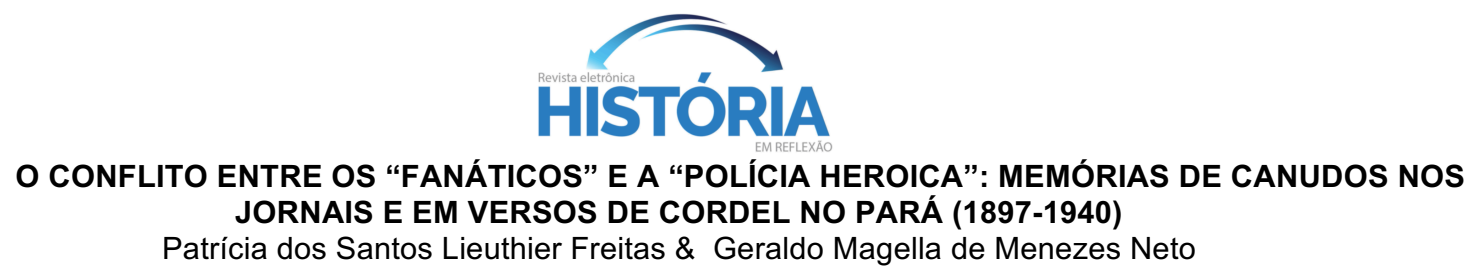

MONIZ, Edmond. Canudos: A luta pela terra. São Paulo: Global, 2001.

MONTEIRO, Welton. Em defesa da República: Os Soldados do Pará na Guerra de Canudos. Belém: Gráfica e Editora R2, 2011.

NEVES, Marilene Nazaré Lins. A Folha do Norte como trincheira política no Pará. Monografia (Bacharelado e Licenciatura Plena em História). Universidade Federal do Pará. Belém, 1993.

NORA, Pierre. Entre memória e história: a problemática dos lugares. Projeto História. São Paulo, No 10, p. 7-28, 1993.

PINHEIRO, Lidiane L. S. A Campanha de Canudos nos jornais. In: INTERCOM- XXVIII Congresso Brasileiro de Ciências da Comunicação. Sessão Temas Livres. Rio de Janeiro: UERJ, 2005.

A construção do acontecimento histórico: o discurso do jornal O Estado de São Paulo sobre a Guerra de Canudos e sobre as comemorações de seu centenário. Tese (Doutorado). Universidade Federal da Bahia. Salvador, 2012.

POLLAK, Michael. Memória, Esquecimento, Silêncio. Estudos Históricos, Rio de Janeiro, vol. 2, n. 3, 1989, p. 3-15.

SÁ, Antonio Fernando de Araújo. Filigramas da memória: história e memória nas comemorações dos centenários de Canudos (1993-1997). Tese (Doutorado). Universidade de Brasília, 2006.

SALLES, Vicente. Repente e Cordel: Literatura popular em versos na Amazônia. Rio de Janeiro: FUNARTE, 1985.

SANTOS, Claude. Armados com lentes. Revista de História da Biblioteca Nacional, Rio de Janeiro, n¹11, p. 26-29, 2014.

SARGES, Maria de Nazaré. Belém: riquezas produzindo a Belle Époque (1870-1912). 3 ed. Belém: Paka-Tatu, 2010.

SILVA, José Maria de Oliveira. A Guerra de Canudos e Os Sertões de Euclides da Cunha: Imaginário popular e revisão Acadêmica. Revista Tempos Históricos, Cascavel, v.03, $n^{\circ} 01$, p. 31-52, 2001.

TERRA, Ruth Brito Lêmos. Memória de lutas: literatura de folhetos do Nordeste (18931930). São Paulo: Global Editora, 1983.

Recebido em: 08/12/2017

Aprovado em: 31/01/2018 